\title{
BMJ Open Is healthcare-seeking with gynaecological alarm symptoms influenced by personal and professional relations? A Danish population-based, cross-sectional study
}

To cite: Vejlgaard AS, Rasmussen S, Jarbøl DE, et al. Is healthcare-seeking with gynaecological alarm symptoms influenced by personal and professional relations? A Danish population-based, crosssectional study. BMJ Open 2020;10:e33471. doi:10.1136/ bmjopen-2019-033471

- Prepublication history for this paper is available online. To view these files, please visit the journal online (http://dx.doi org/10.1136/bmjopen-2019033471).

Received 06 August 2019

Revised 10 March 2020

Accepted 06 April 2020

\section{Check for updates}

(c) Author(s) (or their employer(s)) 2020. Re-use permitted under CC BY-NC. No commercial re-use. See rights and permissions. Published by BMJ.

Research Unit for General Practice, University of Southern Denmark, Odense C, Denmark

Correspondence to Anja Schmidt Vejlgaard; avejlgaard@health.sdu.dk

\section{ABSTRACT}

Objectives To identify the personal and professional relations of women experiencing gynaecological alarm symptoms, to analyse if involving a personal relation is related to healthcare-seeking with gynaecological alarm symptoms, and to analyse if having an available social network is associated with involvement of this relation. Design Web-based, population-based, cross-sectional questionnaire survey.

Setting The general population in Denmark.

Participants The study invited 100000 individuals randomly drawn from the Danish Civil Registration System. Pregnant women and women who did not answer relevant questions about social network were excluded. A total of 5053 women who experienced at least one gynaecological alarm symptom were included in the study.

Primary and secondary outcomes (1) Personal and professional relations that women experiencing gynaecological alarm symptoms involve; (2) the association between involving a personal relation and healthcare-seeking; and (3) the association between having an available social network and involvement of this relation.

Results The general practitioner (GP) was the most involved professional relation, while the spouse/ partner was the most involved personal relation. When experiencing gynaecological alarm symptoms, more than $50 \%$ of women did not involve a professional relation and $20 \%$ did not involve a personal relation. For all four gynaecological alarm symptoms, the odds of involving the GP were higher in the oldest age group. Women were two to seven times more likely to involve their GP if they had personal relation involvement. No statistically significant association was found between having an available social network and involving the GP.

Conclusion Involving a personal relation in healthcareseeking was associated with increased involvement of the GP, who consequently was the most involved professional relation when experiencing gynaecological alarm symptoms. Spouse/partner was the most involved personal relation. The oldest age group had the highest odds of involving the GP. No association was found between having an available social network and involving the GP.

\section{Strengths and limitations of this study}

- This is a large, population-based questionnaire survey that was field-tested and pilot-tested on randomly selected people.

- The study minimised selection bias by giving nonrespondents the option to answer the questionnaire through a telephone interview.

- To minimise recall bias, experiences of symptoms were investigated 4 weeks prior to administering the questionnaire.

- The study has a response rate of $54.5 \%$.

- It is not possible to report the chronological order of relation involvement or respondents' understanding of individual questions.

\section{INTRODUCTION}

Gynaecological cancer is common and accounts for many deaths worldwide. Cervical cancer is the fourth while ovarian cancer the seventh most common type of cancer among women worldwide. ${ }^{1}$ The survival of patients with gynaecological cancers depends on the stage of cancer at diagnosis. The 5-year survival rate of endometrial, ovarian and cervical cancers is more than three times higher at stage I when compared with stage IV. ${ }^{2-4}$

The time frame prior to a cancer diagnosis can be divided into intervals, where patient interval is the time from the first recognition of a symptom to first contact with medical care. ${ }^{56}$ Previous research indicates that gynaecological cancer alarm symptoms are common in the general population $^{78}$ and that less than $50 \%$ of women with alarm symptoms seek medical help. ${ }^{79}$ In light of improved survival with early diagnosis of cancer, this raises the hypothesis that cancer survival can be improved by reducing time to diagnosis (including patient interval). 
Pescolido argues that decision-making related to seeking medical help is a dynamic and complex process depending on the patient's social network, among other factors. ${ }^{10}$ Previous studies have found that for gynaecological cancer in particular, educational level, knowledge that a symptom can be suggestive of cancer, perceiving a symptom as getting worse and persistence of symptoms all affect healthcare-seeking. ${ }^{911}$

For cancer in general, disclosure of cancer symptoms with individuals in their social network reduces patient interval among women. ${ }^{12}$ A previous study based on the Danish Symptom Cohort (DaSC) explored several symptom experiences and revealed that people with an available social network were overall less likely to seek medical help than those without an available social network. ${ }^{13}$ A qualitative interview study of people with symptoms of colorectal and lung cancer indicated that many people discuss their symptom(s) with people in their social network in order to confirm the symptom is not serious or whether they should seek help. ${ }^{14}$

The influences of personal and professional relations among women with gynaecological cancer alarm symptoms have only sparsely been investigated. One study found that social network could influence healthcareseeking both positively and negatively. ${ }^{11}$ Another study found that low levels of social support increased the time before seeking medical help. ${ }^{15}$ The influence of personal and professional relations on healthcare-seeking among women with gynaecological cancer alarm symptoms remains unclear and requires further study.

The aims of this study are to (1) identify which personal and professional relations women involve when experiencing gynaecological alarm symptoms, (2) analyse if involving a personal relation is associated with healthcareseeking, and (3) analyse if having an available social network is related to involving this relation.

\section{METHODS}

Data were obtained from the DaSC, a nationwide, webbased, cross-sectional questionnaire survey. The DaSC invited 100000 randomly drawn invitees from the Danish Civil Registration System (CRS), where all Danish citizens are registered with a personal identification number. ${ }^{16}$ Data were collected between June and December 2012. ${ }^{17}$

The invitees received a postal letter explaining the purpose of the study and a unique 12-digit login code to a secure web page. Non-respondents received a reminder letter after 2 weeks. After an additional 2 weeks they were contacted by telephone and encouraged to participate. In order to prevent exclusion of those without internet access, invitees were offered the possibility of completing the questionnaire through a telephone interview conducted by trained interviewers.

The questionnaire was developed based on standard rating scales and previously validated questionnaires. The specific questions regarding the social network origins from theNational Health interview ${ }^{18}$ which describe items related to general contact with the social network, as well as concern for the respondent's health as expressed by the general practitioner (GP) and the social network. Before sending out the questionnaire, it was pilot-tested and field-tested on 500 randomly selected people from the general population. The questionnaire was then adjusted according to insights gained from the testing. The methodological framework is described elsewhere. ${ }^{17}$

The questionnaire explored 44 different symptoms. The following gynaecological alarm symptoms were used in this study: pelvic pain, pain during intercourse, bleeding during intercourse and postmenopausal bleeding. For each symptom the question was phrased 'Have you experienced any of the following bodily sensations, symptoms or discomfort within the past fourweeks?' In addition to confirming the experience of a symptom, the respondents also had the opportunity to choose 'Do not wish to answer'. Question regarding personal relations was phrased 'Which of the following members of your family or social network have you talked to about the symptoms or discomfort?' (spouse/partner, children, parents, colleague/classmate, friend, neighbour, none and/or other). Questions regarding professional relations were phrased 'Have you contacted your general practitioner with the symptom or discomfort, in person, by phone or by e-mail?' and 'Which of the following other health professionals or therapists have you talked to regarding the symptoms or discomfort?' (another doctor, physiotherapist/chiropractor, home help/district nurse, pharmacy staff, alternative therapist, none and/or other).

For the purpose of analyses, 'family network' covered children and/or parents, while 'non-family network' covered colleagues, friends and/or neighbours. 'Other health professionals' covered physiotherapists or chiropractors, home carers or nurses, pharmacy staff and/or alternative therapists.

In the present paper, the concept of personal and professional relations covers both close and more peripheral acquaintances. The concept 'personal relations' covers the spouse/partner, children, parents, colleagues/classmates, friends and neighbours. The concept 'professional relations' covers GPs, another doctor, physiotherapists/ chiropractors, home carers or nurses, pharmacy staff and alternative therapists.

In order to determine availability of social network, women were asked the following four questions: (1) 'How often are you in contact with friends, acquaintances or family that you do not live with? Contact indicated that you are together, talking with each other on the phone, writing to each other, etc.' (daily or almost daily, once or twice a week, once or several times a month, less than once a month, never or I don't know); (2) 'If you become ill and need help with practical things, can you count on help from others? (Others means people you do not live with)' (yes definitely, yes, maybe or no); (3) 'Does it ever happen that you are alone, even if you want to be in the company of others?' (yes often, yes once in a while, yes but rarely, no, never or almost never); (4) 'Do you have 
someone to talk to if you have problems or need support?' (yes often, yes once in a while, yes but rarely, no, never or almost never). Women were categorised as having an available social network if they answered often in contact with others (daily or almost daily, once or twice a week, or once or several times a month), having people available who can help (yes definitely or yes maybe), not being alone when desiring to be with others (never or almost never, rarely or once in a while) or having a person to talk to in case of problems (often, mostly or sometimes). The same definitions are used elsewhere. ${ }^{13} 19$

\section{Patient and public involvement}

The public were involved in the development of the study, both in pilot testing and in field testing of the questionnaire. The pilot testing included seven women and four men who were recruited and observed while completing the questionnaire. A trained interviewer asked each participant to comment on the questions and possible problems they could foresee while completing the questionnaire. ${ }^{17}$ The questionnaire was then field-tested among 500 Danish adults who were randomly selected using the CRS. Patients were not involved in developing the research questions and outcome measures, in the study design, in the recruitment process, or in the conduct of the survey. The results of the study will be accessible for GPs and other health professionals in scientific journals.

\section{Data analysis}

Women reporting at least one gynaecological alarm symptom were included in the statistical analyses. Pregnant women were excluded as they may display a different healthcare-seeking pattern and symptoms may be related to pregnancy. Respondents answering 'Do not wish to answer' on one or more gynaecological alarm symptom were included in the study as they might also add valuable information about other alarm symptoms. However, these respondents answering 'Do not wish to answer' were categorised as not having that gynaecological alarm symptom and were thus excluded from further analyses on that particular symptom. Additionally, respondents who answered 'Do not wish to answer' were not presented with subsequent questions that ask them to elaborate on that particular symptom.

Descriptive analyses were used to explore which personal and professional relations were involved when experiencing a gynaecological alarm symptom.

Age-stratified analyses were performed for each gynaecological alarm symptom using the following age groups: $<40$ years, $40-59$ years and $\geq 60$ years.

Multivariate logistic regression models were used to analyse possible associations between several variables and involvement of GP, other doctors, spouse/partner, family network or non-family network. Variables included age, number of gynaecological alarm symptoms, having an available social network and involving a personal relation. Crude and adjusted ORs were calculated and adjustments were made for all variables.

All analyses were conducted using STATA V.14.1 statistical software.

\section{RESULTS}

In total, 26466 of the invited women completed the questionnaire, yielding a response rate of $54.5 \%$. Of these, 24659 women answered all the relevant questions regarding involvement of relations and the social network and 19616 did not experience gynaecological alarm symptoms. In total, 5043 women answered all the relevant questions, reported at least one gynaecological alarm symptom and were eligible for analysis (figure 1).

Descriptive data of the study population are shown in table 1 . The prevalence of gynaecological symptoms varied from $1.3 \%$ for postmenopausal bleeding to $14.5 \%$ for pelvic pain.

More than half of the respondents did not involve a professional relation when experiencing a gynaecological alarm symptom. When a professional relation was involved, it was most frequently with the GP. GP involvement varied from $25.4 \%$ for pelvic pain to $33.2 \%$ for postmenopausal bleeding. Involvement of other doctors varied from $20.8 \%$ for pelvic pain to $30.8 \%$ for postmenopausal bleeding.

The proportion of women who did not involve a personal relation ranged from $21.1 \%$ for pain during intercourse to $29.0 \%$ for postmenopausal bleeding. For all symptom experiences the most frequently involved personal relation was the spouse/partner, whose involvement varied from $46.4 \%$ for postmenopausal bleeding to $74.9 \%$ for pain during intercourse. The second most involved personal relation was a friend, who was involved in $15 \%$ of cases with pelvic pain and up to $21.0 \%$ of cases with pain during intercourse.

The proportion of women who did not involve a relation, neither personal nor professional, varied from $17.2 \%$ for pain during intercourse to $29.0 \%$ for bleeding during intercourse.

Table 2 lists the involvement of personal and professional relations stratified by age. For all gynaecological alarm symptoms, the percentage of women involving a GP was highest in the oldest age group.

The odds of involving the GP, other doctors, spouse/ partner, family network and/or non-family network for each gynaecological alarm symptom are shown in tables 3-4, with each table containing two of the four symptoms: table 3 contains pelvic pain and pain during intercourse, while table 4 contains bleeding during intercourse and postmenopausal bleeding.

For all four gynaecological alarm symptoms, involving a personal relation was statistically significantly associated with increased odds of involving the GP and/or other doctor compared with those not involving any personal relations. 


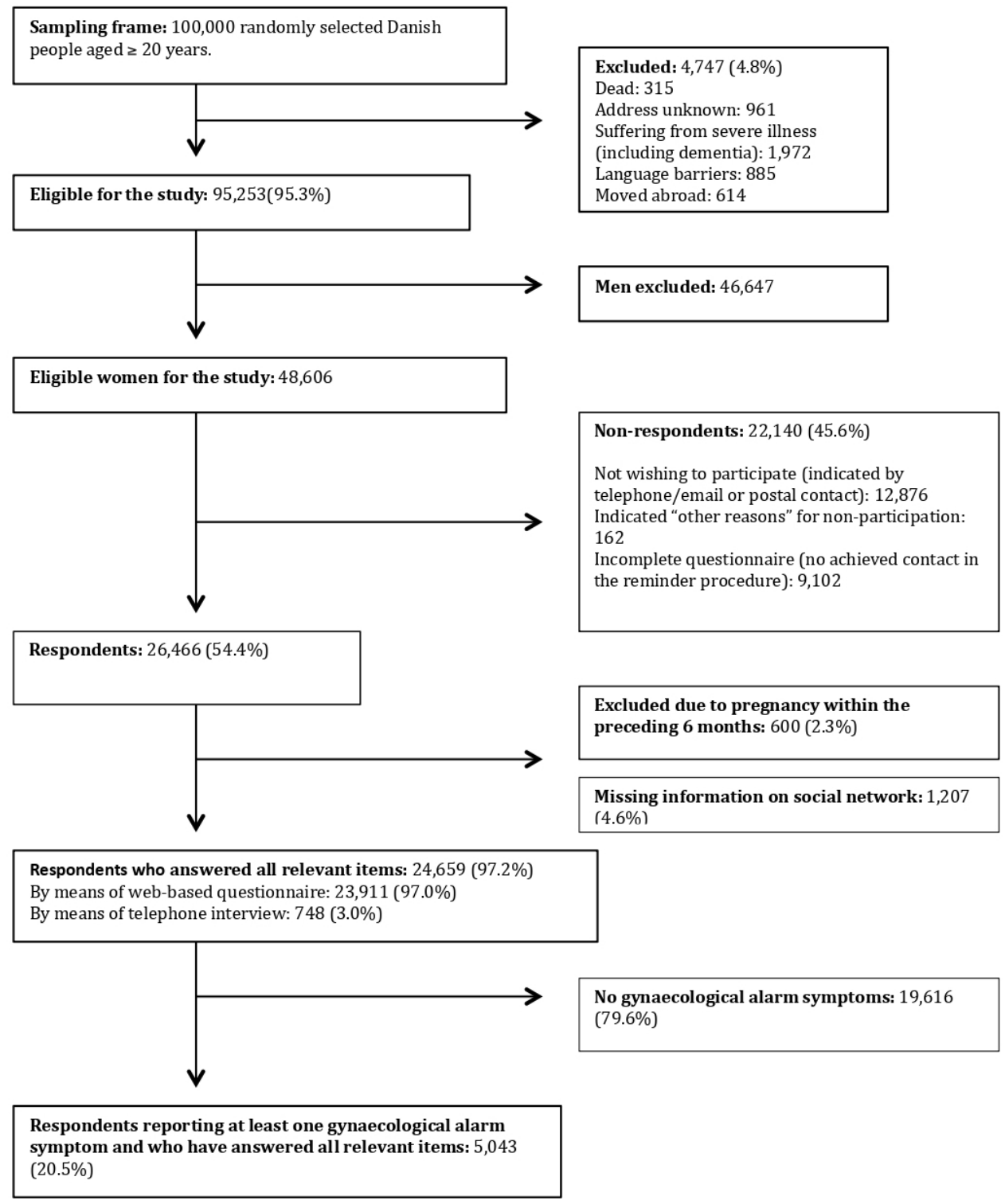

Figure 1 Flow of participants.

Among women experiencing pelvic pain, pain during intercourse or bleeding during intercourse, significantly higher odds of involving the GP and/or other doctors were observed in the $\geq 60$ years age group compared with those $<40$ years of age. For the same symptoms, the odds of involving the non-family network were significantly lower among the $<40$ age group compared with the $\geq 60$ years old age group, while women between 40 and 59 years of age had significantly lower odds of involving the family network compared with women $<40$ years of age.

Women who experienced pelvic pain or pain during intercourse with two or more gynaecological alarm symptoms had higher odds of involving the GP and/or other doctors than women who experienced only one symptom. For women experiencing bleeding during intercourse, the odds of involving another doctor were higher for women experiencing three symptoms compared with those experiencing only one symptom. Women experiencing pelvic pain had higher odds of involving the spouse/partner if they experienced two or three symptoms compared with experiencing only one gynaecological symptom.

For women experiencing pelvic pain and pain during intercourse, having an available social network was associated with higher odds of involving the spouse/partner and non-family network compared with those without an available social network. For women experiencing bleeding during intercourse, having an available social network was associated with lower odds of involving family network. No significant association was found between having an available social network and involving the GP or other doctors.

\section{DISCUSSION}

\section{Summary}

Out of the population-based survey of 26,466 female respondents, a total of 5,043 womenform the basis of this study. The GP was the most involved professional relation 
Table 1 Descriptive data of the study classified by type of gynaecological alarm symptom

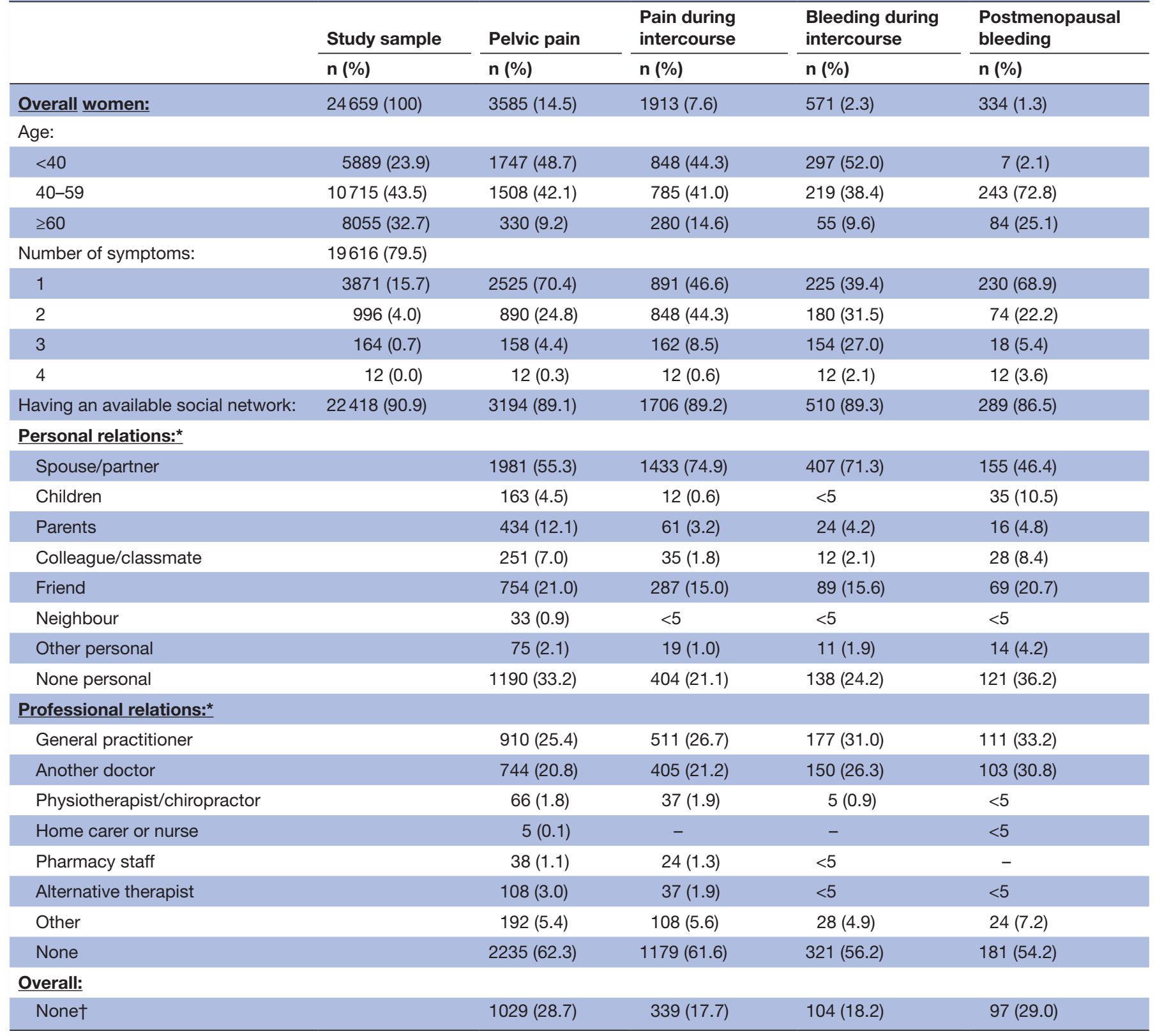

${ }^{*}$ Responses are based on the individual: percentages do not total 100 because one individual can involve more than one personal and/or professional relation when experiencing the same symptom.

†None means that neither a professional nor a personal relation was involved when experiencing symptoms.

in all four gynaecological alarm symptoms. More than half of women did not involve a professional relation when experiencing gynaecological alarm symptoms. The spouse/partner was the most involved personal relation, while a friend was the second most involved. Between $17.7 \%$ and $29.0 \%$ of women did not involve either a personal or a professional relation when they experience gynaecological alarm symptoms.

Involvement of a personal relation was associated with twofold to sevenfold increased odds of involving the GP or another doctor in all four gynaecological alarm symptoms.
The results showed higher odds of involving the GP and/or another doctor among women experiencing pelvic pain, pain during intercourse and bleeding during intercourse and who were $\geq 60$ years of age compared with those $<40$ years of age. For the same symptoms, the experience of two or three symptoms was associated with higher odds of involving the spouse/ partner, compared with experiencing only one gynaecological symptom.

This study found no significant association between having an available social network and involvement of the GP or other doctors. 


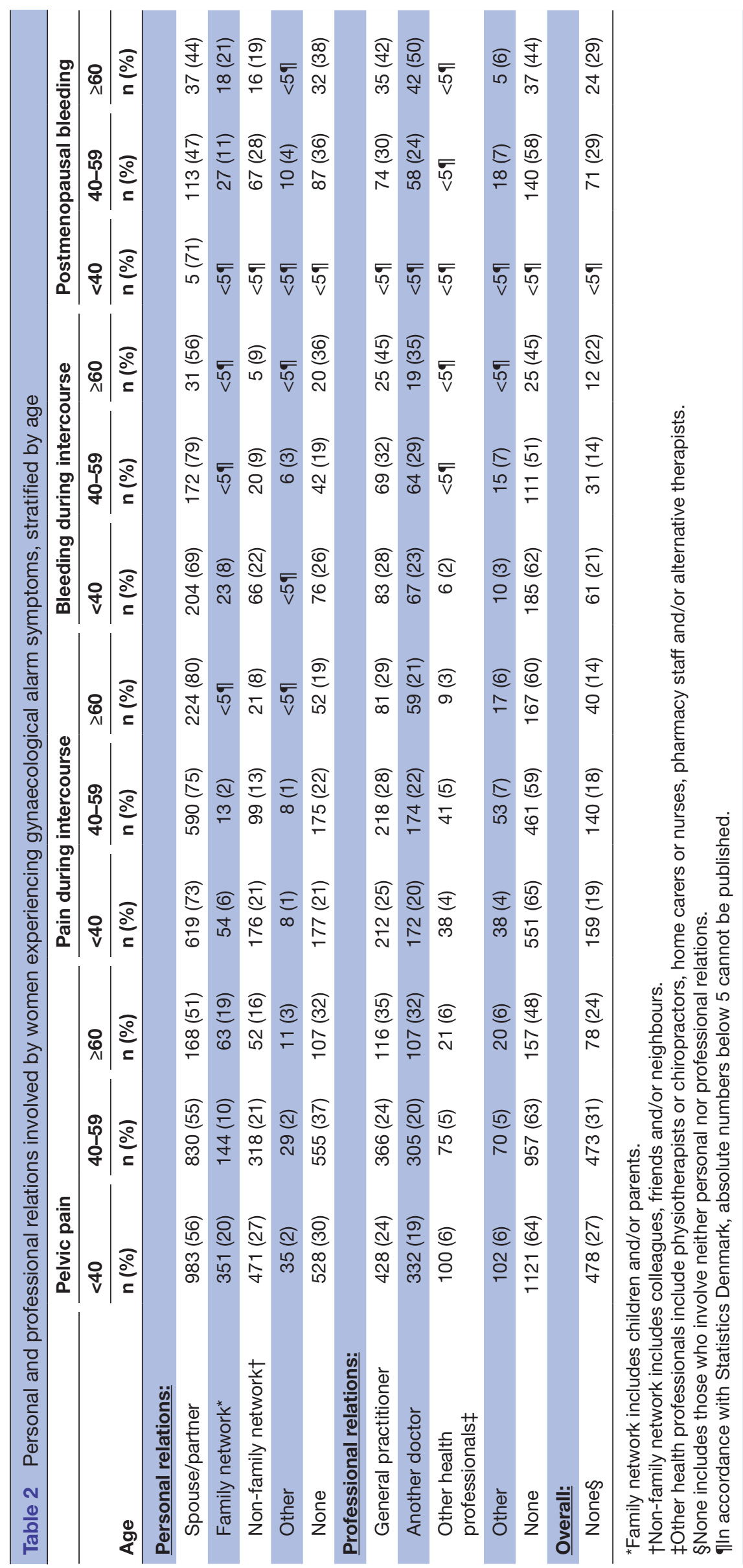




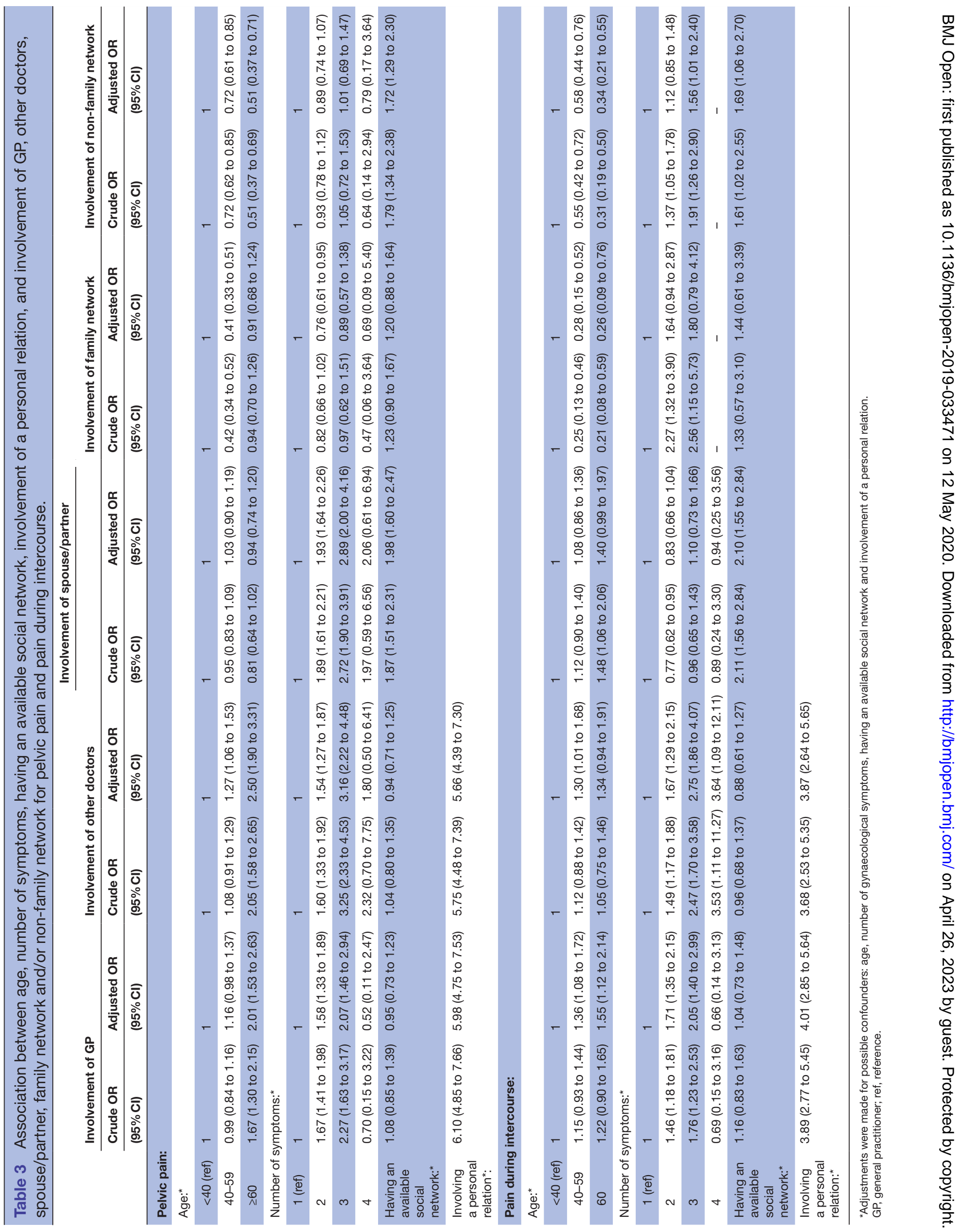




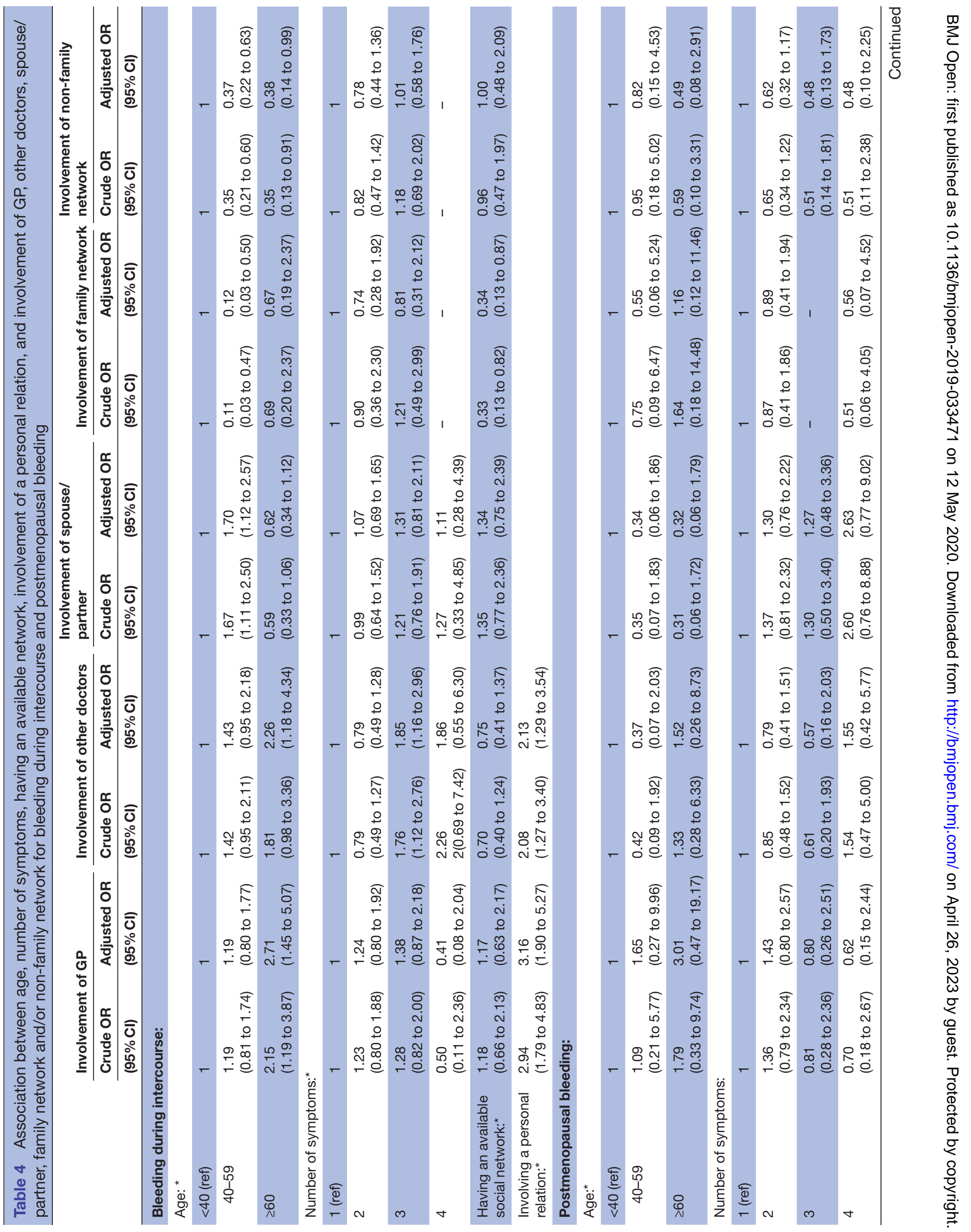




\section{Strengths and limitations}

This study was conducted using a national, cross-sectional, population-based questionnaire survey of $100 \quad 000$ randomly selected Danish citizens. To our knowledge, such a large-scale, population-based study on the association between involvement of personal and professional relations and healthcare-seeking among women with gynaecological alarm symptoms has not previously been conducted. The response rate of $54.5 \%$ is higher than or comparable with previous population-based studies. ${ }^{7}$ An analysis comparing respondents with non-respondents showed that the median age of respondents (52, IQR 40-64) was slightly higher than that of non-respondents (50, IQR 36-66). Additionally, the respondents were more often female, married/living together, with higher education and with higher income level, and were more often attached to the labour market. The differences between respondents and non-respondents could be a limitation of this study; however, the respondents were found to be representative of the general Danish population. ${ }^{20}$

To minimise selection bias, those without internet access were offered the option of answering the questionnaire through a telephone interview; $3 \%$ of the respondents used this option. Additionally, the invitees were randomly selected through CRS, which also minimises selection bias.

Respondents were asked about symptom experiences within the previous 4 weeks to minimise recall bias. Four weeks is a short time period; but if a respondent forgot anexperienced symptom or involvement of a relation, this could lead to an underestimation ofthe results.

Using a population-based design instead of a design with patients already diagnosed with cancer helps minimise information bias. Getting labelled with a diagnosis, can change a person's view of the course leading up to getting the diagnosis and initial thoughts about an experienced symptom. This is avoided by using a populationbased design where people are asked about symptom experiences regardless of disease diagnosis.

With regard to the development of the questionnaire, the questionnaire was field-tested and pilot-tested with the aim of knowing how respondents would interpret the questions; this was done to avoid misinterpretation. However, some respondents might have interpreted and answered the questionnaire differently from what was intended. Additionally, the chronological order of involvement cannot be determined, and the study can only describe which personal and professional relations were involved. Likewise, the quality of the involved relations and the advice given are unknown as these were not explored in the questionnaire.

'Do not wish to answer', which was a response option for each of the gynaecological alarm symptoms, was selected by fewer than $5 \%$ of the respondents; however, these respondents were also included in the analysis because they might have answered other questions which could add valuable information to the analysis. These respondents were included in the analysis as not having 
particular symptoms. A previous study conducted two sensitivity analyses on the effect of including respondents answering 'Do not wish to answer' as not having the symptom. Whether or not these women were included in the analysis as having or not having experienced the symptom did not affect the results. ${ }^{8}$

In Denmark, the GP functions as a gatekeeper and is responsible for referral to specialists, such as gynaecologists. ${ }^{21}$ Additionally, healthcare services are free of charge, so a high involvement with the GP could be expected, compared with countries that charge user fees. ${ }^{21}{ }^{22}$ The results of this survey might be comparable with other Western countries with a highly developed healthcare system and with similar culture as Denmark.

\section{Comparison with existing literature}

The most noticeable finding in this study is that involvement of a personal relation increases the odds of involving the GP in all gynaecological alarm symptoms, which corresponds with previous studies. Pescolido stated that network interactions contribute to the process of deciding whether something is wrong and what should be done about it. ${ }^{10}$ Brandner et al ${ }^{23}$ stated that discussing an experienced bodily sensation with a personal relation can help interpret the sensation and is important for healthcare-seeking. Other studies suggest that culture, norms and relations affect the interpretation of bodily sensations, therefore affecting the healthcare-seeking behaviour. ${ }^{24} 25$

A study examining deprived communities found that support from family and friends increased the likelihood of healthcare-seeking. ${ }^{26}$ Results from studies on cancer in general have shown that family and friends can facilitate healthcare-seeking by legitimising it and helping people face up to their fears. ${ }^{22} 27$ To the authors' knowledge, only one study has examined the association between involvement of personal relations and healthcare-seeking among women with gynaecological alarm symptoms. This qualitative interview study found that the experiences of others could influence the decision-making process of seeking healthcare. ${ }^{11}$ Another study on the DaSC population examining women with symptoms of urinary incontinence found three to four times increased odds of involving the GP when involving a personal relation, ${ }^{19}$ which is similar to the association found in this study. Conclusions on the chronological order of involvement cannot be made due to the study's questionnaire design. Nonetheless, previous studies suggest that it is the involvement of a personal relation that prompts involvement of the GP. ${ }^{1426}$

The involvement of the GP ranged from $25.4 \%$ for pelvic pain to $33.2 \%$ for postmenopausal bleeding, which is comparable with the findings of another study on symptoms indicative of gynaecological cancer conducted in the UK. ${ }^{7}$ Another study examining 10 symptoms of cancer in general found that $51 \%$ of the individuals involved the GP. This percentage is high compared with the involvement of the GP in our study and might be due to different time frames of interest. Moreover, they examined 10 different cancer alarm symptoms, and healthcare-seeking depends on what category the symptoms fall within. ${ }^{28}$ This might explain the differences in GP involvement.

The most frequently involved personal relation in our study was the spouse/partner, followed by a friend. Another study on gynaecological alarm symptoms also found that the influence of close family members was especially important for healthcare-seeking. ${ }^{11}$ A study on colorectal and lung cancer symptoms found that most people discussed their symptoms with others, most often their spouse, but also with family and friends. ${ }^{14}$ The findings of the present study also correspond with recent studies, suggesting that especially spouses, children and friends are important for healthcare-seeking. ${ }^{23}$

In the present study the association between having an available social network and involving the GP was examined. Except for pain during intercourse and pelvic pain, where the odds of involving the spouse/partner or non-family network were higher among women with an available social network compared with women without, no other significant associations were found. For women experiencing bleeding during intercourse, the odds of involving family network were lower if they had an available social network compared with not having one. Besides the two previous studies on the DaSC population, no studies examining the impact of having an available social network were found. ${ }^{13} 19$ Elnegaard $e t a l^{13}$ examined many different symptom experiences and found that people with an available social network were more likely to involve personal relations and less likely to involve the GP and other doctors. The present study hypothesised that women without an available social network involve the GP more than women with an available social network, as this might be their available relation in case of symptoms. No significant results for the association between not having an available social network and involving the GP were found. This may be due to the small groups of women who experienced each of the four gynaecological alarm symptoms and could imply a statistical power issue.

Involvement of neither personal nor professional relations ranged from $17.7 \%$ for pain during intercourse to $29.0 \%$ for postmenopausal bleeding. Other studies suggest that some women do not involve professional relations because they do not want to waste the doctor's time, ${ }^{11}$ or do not involve personal relations because they do not want to worry others. ${ }^{14}$ Another study also suggests that healthcare-seeking can be delayed due to personal responsibilities and taking care of others first. ${ }^{23}$ The current study cannot comment on why some women do not involve personal or professional relations.

Consistent with other studies, it was found that the odds of involving the GP were higher among the oldest age group compared with the youngest. ${ }^{728}$

\section{Implications for research and/or practice}

There are only a few existing studies which examine the role of personal and professional relations in 
healthcare-seeking among women with gynaecological alarm symptoms. This study adds new information to this research area. The design is population-based and the results can be used by GPs, among others. According to our results, women involving personal relations are more likely to involve their GP. Although the study cannot comment on the chronological order of involvement, the results of this study can probably be used by GPs to consider women without personal relationships as having a higher risk of not seeking medical help when experiencing gynaecological alarm symptoms. Thereby, GPs can try to identify these women during consultation for other health issues. GPs can inform these women about the nature of the symptoms and the importance of early healthcare-seeking aiming to rule out the possibility of cancer. They must also inform these women that most symptoms will not result in a diagnosis of cancer. ${ }^{29}$

Previous literature has shown that involving a person relation can lead to GP involvement ${ }^{1022} 27$; therefore, future health campaigns regarding help-seeking with cancer alarm symptoms must not only target women experiencing gynaecological alarm symptoms but also their relations.

Only about $10 \%$ of women reported not having an available social network; thus, a strong conclusion could not be made about the possible association between not having an available social network and involving the GP based on the present study. The effect that availability and involvement of social network have on healthcare-seeking should be further explored in future studies.

\section{CONCLUSION}

Involving a personal relation increased the odds of involving the GP in all four gynaecological cancer alarm symptoms. The most involved professional relation was the GP, while the most involved personal relation was the spouse/partner, followed by a friend. The odds of involving the GP were higher in the oldest age group compared with the youngest age group. No association was found between having an available social network and involving the GP.

\section{Acknowledgements The authors would like to thank Maria Munch Storsveen for} statistical guidance.

Contributors The questionnaire on which the study was based was developed by $\mathrm{SR}, \mathrm{KB}$ and DJ. All authors contributed to the design of the study and interpretation of data. ASV and SR conducted the statistical analyses. ASV drafted the manuscript, while SR, DJ and KB critically revised it for important intellectual content. All authors read and approved the final manuscript and agree to be held accountable for all aspects of their work.

Funding This study was financially supported by The Lundbeck Foundation. The funding source had no influence on the study or approval of the manuscript.

\section{Competing interests None declared.}

Patient and public involvement Patients and/or the public were involved in the design, or conduct, or reporting, or dissemination plans of this research. Refer to the Methods section for further details.

Patient consent for publication Not required.
Ethics approval The project has been approved by the Danish Data Protection Agency (file number 2011-41-6651). The Regional Scientific Ethics Committee for Southern Denmark did not find that the project needed to be reviewed. The participants were informed that there was no clinical follow-up, and that if they had any concerns or worries they should contact their general practitioner.

Provenance and peer review Not commissioned; externally peer reviewed.

Data availability statement Data may be obtained from a third party and are not publicly available. The data sets generated and analysed in the current study are not publicly available according to the General Data Protection Regulation (GDPR) and the Danish Data Protection Act, established by Statistics Denmark and Danish Health Authority. Access to data is strictly limited to the researchers who have obtained permission for data processing. This permission was given to the Research Unit of General Practice, Department of Public Health and University of Southern Denmark.

Open access This is an open access article distributed in accordance with the Creative Commons Attribution Non Commercial (CC BY-NC 4.0) license, which permits others to distribute, remix, adapt, build upon this work non-commercially, and license their derivative works on different terms, provided the original work is properly cited, appropriate credit is given, any changes made indicated, and the use is non-commercial. See: http://creativecommons.org/licenses/by-nc/4.0/.

\section{ORCID iD}

Anja Schmidt Vejlgaard http://orcid.org/0000-0002-3567-4799

\section{REFERENCES}

1 Ferlay J, Soerjomataram I, Dikshit R, et al. Cancer incidence and mortality worldwide: sources, methods and major patterns in GLOBOCAN 2012. Int J Cancer 2015;136:E359-86.

2 Creasman WT, Odicino F, Maisonneuve P, et al. Carcinoma of the corpus uteri. FIGO 26th annual report on the results of treatment in gynecological cancer. Int J Gynaecol Obstet 2006;95 Suppl 1:S105-43.

3 Quinn MA, Benedet JL, Odicino F, et al. Carcinoma of the cervix uteri. FIGO 26th annual report on the results of treatment in gynecological cancer. Int J Gynaecol Obstet 2006;95 Suppl 1:S43-103.

4 Heintz APM, Odicino F, Maisonneuve P, et al. Carcinoma of the ovary. FIGO 26th annual report on the results of treatment in gynecological cancer. Int J Gynaecol Obstet 2006;95 Suppl 1:S161-92.

5 Allgar VL, Neal RD. Delays in the diagnosis of six cancers: analysis of data from the National survey of NHS patients: cancer. $\mathrm{Br} J \mathrm{Cancer}$ 2005;92:1959-70.

6 Weller D, Vedsted P, Rubin G, et al. The Aarhus statement: improving design and reporting of studies on early cancer diagnosis. $\mathrm{Br} \mathrm{J}$ Cancer 2012;106:1262-7.

7 Low EL, Simon AE, Waller J, et al. Experience of symptoms indicative of gynaecological cancers in UK women. Br J Cancer 2013;109:882-7.

8 Balasubramaniam K, Ravn P, Larsen PV, et al. Specific and unspecific gynecological alarm symptoms--prevalence estimates in different age groups: a population-based study. Acta Obstet Gynecol Scand 2015;94:191-7.

9 Balasubramaniam K, Ravn P, Christensen RD, et al. Gynecological cancer alarm symptoms: is contact with specialist care associated with lifestyle and socioeconomic status? a population-based study. Acta Obstet Gynecol Scand 2016;95:976-83.

10 BA P. Beyond rational choice: the social dynamics of how people seek help. Am J Sociol 1992;97:1096-138.

11 Low EL, Whitaker KL, Simon AE, et al. Women's interpretation of and responses to potential gynaecological cancer symptoms: a qualitative interview study. BMJ Open 2015;5:e008082.

12 Pedersen AF, Olesen F, Hansen RP, et al. Gender and patient delay. Br J Cancer 2011;104:1249-55.

13 Elnegaard S, Andersen RS, Pedersen AF, et al. Activation of professional and personal network relations when experiencing a symptom: a population-based cross-sectional study. BMJ Open 2017;7:e017620.

14 Dobson C, Russell A, Brown S, et al. The role of social context in symptom appraisal and help-seeking among people with lung or colorectal symptoms: a qualitative interview study. Eur J Cancer Care 2018;27:e12815.

15 Macleod U, Mitchell ED, Burgess C, et al. Risk factors for delayed presentation and referral of symptomatic cancer: evidence for common cancers. Br J Cancer 2009;101 Suppl 2:S92-101.

16 Pedersen CB, Gøtzsche H, Møller JO, et al. The Danish civil registration system. A cohort of eight million persons. Dan Med Bull 2006;53:441-9. 
17 Rasmussen S, Søndergaard J, Larsen PV, et al. The Danish Symptom Cohort: Questionnaire and Feasibility in the Nationwide Study on Symptom Experience and Healthcare-Seeking among 100000 Individuals. Int J Family Med 2014;2014:187280-10.

18 Christensen A, Ekholm O, Davidsen M, et al. Sundhed og sygelighed i Danmark 2010 \& udviklingen siden 1987[Health and morbidity in Denmark 2010 and developments since 1987. Copenhagen: Statens Institut For Folkesundhed, 2012.

19 Raasthøj I, Elnegaard S, Rosendal M, et al. Urinary incontinence among women-which personal and professional relations are involved? a population-based study. Int Urogynecol $J$ 2019;30:1565-74.

20 Elnegaard S, Andersen RS, Pedersen AF, et al. Self-reported symptoms and healthcare seeking in the general population-exploring "The Symptom Iceberg". BMC Public Health 2015;15:685.

21 Pedersen KM, Andersen JS, Søndergaard J. General practice and primary health care in Denmark. J Am Board Fam Med 2012;25 Suppl 1:S34-8.

22 Smith LK, Pope C, Botha JL. Patients' help-seeking experiences and delay in cancer presentation: a qualitative synthesis. Lancet 2005;366:825-31.

23 Brandner S, Müller-Nordhorn J, Stritter W, et al. Symptomization and triggering processes: ovarian cancer patients' narratives on pre-diagnostic sensation experiences and the initiation of healthcare seeking. Soc Sci Med 2014;119:123-30.

24 Andersen RS, Nichter M, Risør MB. Sensations, symptoms and healthcare seeking. Anthropology in Action 2017;24:1-5.

25 Fainzang S, Haxaire $\mathrm{C}$. The process of symptomization clinical encounters with functional disorders. In: Of bodies and symptoms anthropological perspectives on their social and medical treatment, 2011: 21-39.

26 Smits S, McCutchan G, Wood F, et al. Development of a behavior change intervention to encourage timely cancer symptom presentation among people living in deprived communities using the behavior change wheel. Ann Behav Med 2018;52:474-88.

27 Leydon GM, Bynoe-Sutherland J, Coleman MP. The journey towards a cancer diagnosis: the experiences of people with cancer, their family and carers. Eur J Cancer Care 2003;12:317-26.

28 Williams P, Murchie P, Bond C. Patient and primary care delays in the diagnostic pathway of gynaecological cancers: a systematic review of influencing factors. Br J Gen Pract 2019;69:e106-11.

29 Svendsen RP, Støvring H, Hansen BL, et al. Prevalence of cancer alarm symptoms: a population-based cross-sectional study. Scand $J$ Prim Health Care 2010;28:132-7. 